\title{
Changes in the Expression of Myosins During Postnatal Development of Masseter Muscle in the Microphthalmic Mouse
}

\author{
R. Katayama ${ }^{1}$, A. Yamane ${ }^{2 *}$ and T. Fukui ${ }^{3}$ \\ ${ }^{I}$ Orthodontic Science, Graduate School of Tokyo Medical and Dental University, Tokyo, Japan \\ ${ }^{2}$ Department of Biophysics, Tsurumi University School of Dental Medicine, Yokohama, Japan \\ ${ }^{3}$ Department of Orthodontics, Tsurumi University School of Dental Medicine, Yokohama, Japan
}

\begin{abstract}
In the present study, to elucidate the influences of the deficiency of teeth on the masseter muscle, we analyzed changes in the expression of MyHC isoform mRNAs during postnatal development in $\mathrm{mi} / \mathrm{mi}$ mice using real-time PCR. By 8 weeks of age, MyHC I had nearly disappeared in the $+/+$ mice, while it was still present in the $m i / m i$, and the level of MyHC I mRNA in the mi/mi was 5.1-fold higher than that in the $+/+(\mathrm{p}<0.01)$. The levels of MyHC IIx mRNAs in the $\mathrm{mi} / \mathrm{mi}$ mice were $41 \sim 55 \%$ lower than those in the $+/+$ at both 3 weeks and 4 weeks of age ( $<<0.05)$. No significant difference in the expression of MyHC IIa and IIb mRNAs in the masseter muscle was found between the $m i / m i$ and $+/+$. From these results, we speculate that the deficiency of teeth affects the masseter muscles during the postnatal development.
\end{abstract}

Keywords: Masseter Muscle, Postnatal Development, Microphthalmic Mouse, mRNA.

\section{INTRODUCTION}

The masseter muscle is a jaw-closing muscle with unique characteristics that make it distinct from limb and trunk muscles [1,2]. It is well known that, by the time of tooth eruption, the feeding behavior of rats and mice changes from suckling to chewing, which usually occurs between 17 and 25 days after birth [3]. During this postnatal period, many drastic changes occur in the masseter muscle: the myofibers grow rapidly and markedly [4,5], myosin heavy chain (MyHC) neonatal isoform mostly disappears [5], the diameter of the motoneurons innervating the masseter muscle increases, and the motoneuron electromyographic pattern changes [5,6]. Synaptic formation in the neuromuscular junction rapidly progresses in the masseter muscle before and after this transition in feeding behavior [7]. However, the roles of both tooth eruption and the initiation of occlusal activity on the masseter muscle have yet to be determined.

MyHC, a major contractile protein in skeletal muscles, is encoded by a family of genes consisting of at least six isoforms, including the embryonic, neonatal, I, IIa, IIx, and IIb isoforms [8]. MyHC I is mainly expressed in slow-twitch myofibers, whereas MyHC IIa, IIx, and IIb are expressed in fast-twitch fibers. These isoforms differ in their contractile and metabolic properties, and are capable of adapting their phenotypes to meet functional demands during postnatal development. For example, mechanical unloading can alter limb muscles sequentially toward a faster isoform in the following sequence: $\mathrm{I} \rightarrow \mathrm{IIa} \rightarrow \mathrm{IIx} \rightarrow \mathrm{IIb}[8,9]$. For this reason, they are often used as indicators of certain skeletal muscle properties.

*Address correspondence to this author at the Department of Biophysics, Tsurumi University School of Dental Medicine, 2-1-3 Tsurumi, Tsurumi-ku, Yokohama, 230-8501 Japan; Tel: +81-45-580-8460; Fax: +81-45-573-9599 E-mail: yamane-a@tsurumi-u.ac.jp
The microphthalmic mouse $(\mathrm{mi} / \mathrm{mi})$ has a $3 \mathrm{nt}$ deletion at the locus of the microphthalmia-associated transcription factor gene (mitf) that results in a loss of asparagines residue in the basic domain of the mitf protein [10,11]. The homozygote mutation at the mitf locus affects the ability of the mitf protein to bind DNA and induces small eyes, a devoid of pigment, deaf at an early age, a decrease of mast cells and immunological defects. Most homozygotes die around weaning but some may live for several months. A deficiency of bone resorption caused by abnormal osteoclast development prevents tooth eruption $[12,13]$. We recently reported that, in the masseter of $\mathrm{mi} / \mathrm{mi}$ mice, synaptogenesis at the neuromuscular junction fails to progress normally, suggesting that the eruption of teeth is essential for normal synaptogenesis [14]. The present study attempts to elucidate the role of tooth deficiency (especially the lack of occlusal activity) on the masseter muscles by analyzing changes in the expression of MyHC isoform mRNAs during the postnatal development of masseter muscle in $\mathrm{mi} / \mathrm{mi}$ mice.

\section{MATERIALS AND METHODS}

\section{Animals}

A breeding pair of mice heterozygous for the mitf mutation $(\mathrm{mi} /+$ male and $\mathrm{mi} /+$ female) (strain name, $\mathrm{B} 6 \mathrm{C} 3 \mathrm{Fe}$ a/a$M i t f^{m i} / J$ ) was purchased from the Jackson Laboratory (Bar Harbor, Maine, USA). Homozygous mutant $(\mathrm{mi} / \mathrm{mi})$ and wild-type $(+/+)$ mice were obtained by mating this breeding pair. The pups were breast-fed and removed from their dams at about 3 weeks after birth. After weaning, the $m i / m i$ mice were fed a powder diet and the $+/+$ mice were fed a pellet diet (CE-2, CLEA Japan, Inc., Tokyo, Japan) (Fig. 1A). The $\mathrm{mi} / \mathrm{mi}$ and $+/+$ mice were killed by cervical dislocation under ether anesthesia at 1, 2, 3, 4, and 8 weeks of age, and the masseter and gastrocnemius muscles were dissected out and weighed. The design for the experiment and pictures of the 

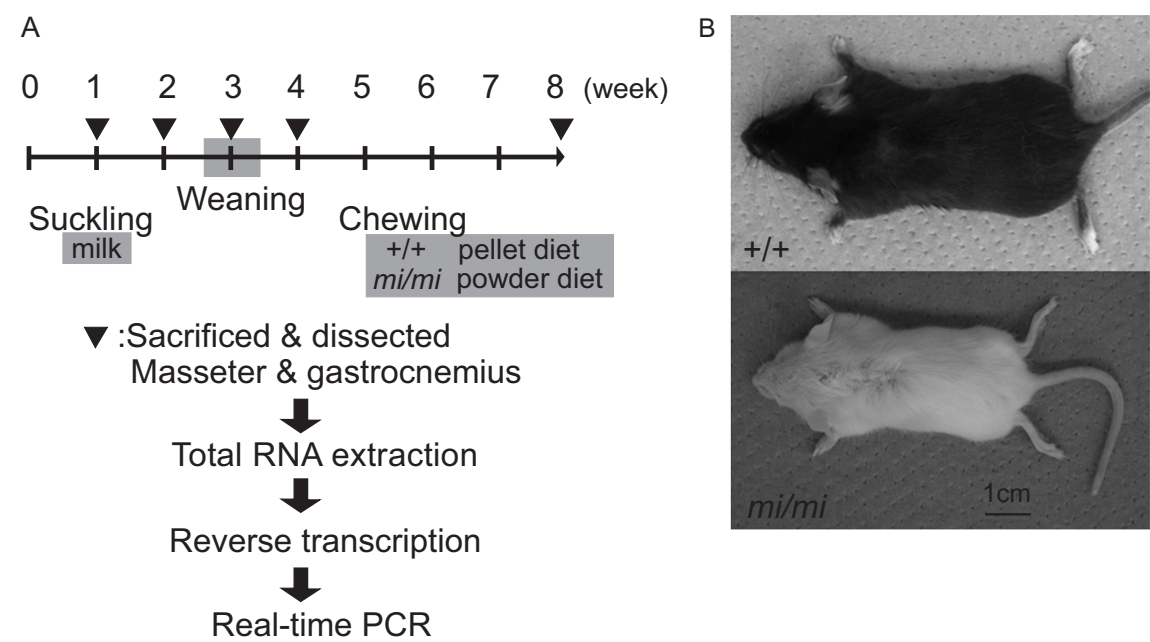

Fig. (1). The design for the experiment (A) and pictures of $m i / m i$ and $+/+$ at 4 weeks of age (B).

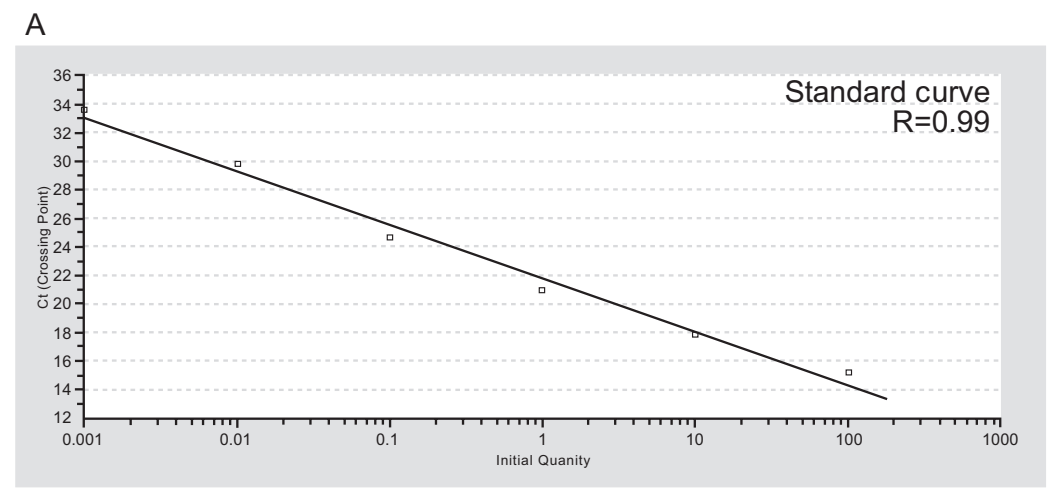

B

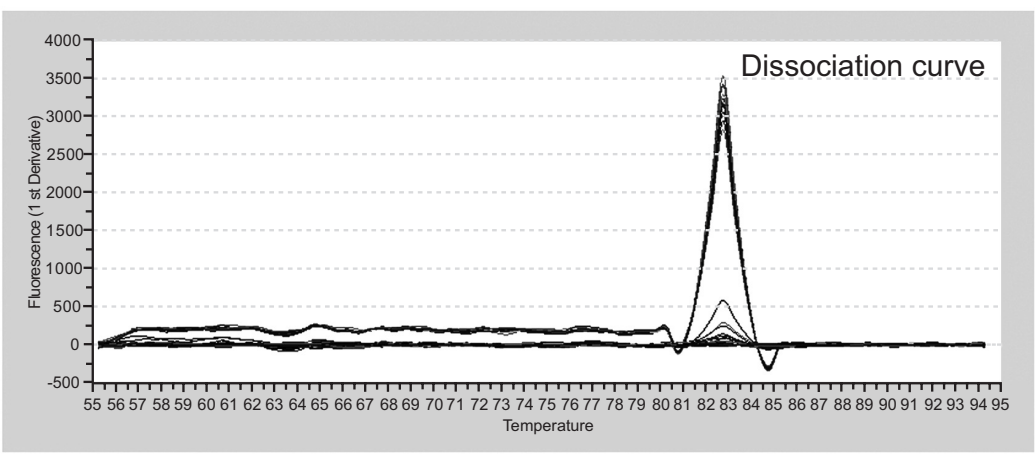

Fig. (2). The representative standard curve (A) and dissociation curve (B) for S16, a ribosomal protein. R: correlation coefficient.

$\mathrm{mi} / m i$ and $+/+$ were shown in Fig. (1). The muscle samples were immediately frozen and stored at $-80^{\circ} \mathrm{C}$ until use. All experimental protocols concerning animal handling were reviewed and approved by the Institutional Animal Care Committee of Tsurumi University School of Dental Medicine.

\section{Quantitative RT-PCR}

Total RNA extraction, treatment with deoxyribonuclease $\mathrm{I}$, and reverse transcription were performed as previously described [15]. Briefly, total RNA extraction was performed according to the manufacturer's specifications (Trizol, Life Technologies, Gaithersburg, MD, USA). The RNA was treated with 2 units of ribonuclease-free deoxyribonuclease I
(Life Technologies, Gaithersburg, MD, USA), and $1.5 \mu \mathrm{g}$ of the RNA was then reverse transcribed to cDNA with 200 units of reverse transcriptase (SuperScript II, Life Technologies, Gaithersburg, MD, USA). The cDNA (20 ng) was used for the one real-time PCR reaction.

SYBR Green real-time PCR was performed on the ABI PRISM 7700 instrument (Applied Biosystems, Foster City, CA, USA) using the following cycle parameters for all genes studied: denaturation at $95^{\circ} \mathrm{C}$ for $10 \mathrm{~min}$, followed by 40 cycles of $95^{\circ} \mathrm{C}$ for $15 \mathrm{~s}$ for denaturation, and $55^{\circ} \mathrm{C}$ for $15 \mathrm{~s}$ for annealing and extension. The representative standard curve and dissociation curve for S16, ribosomal protein, were shown in Fig. (2). We verified that correlation coefficients of 


\section{Table 1. Sequences of PCR Primers Specific to Target Genes}

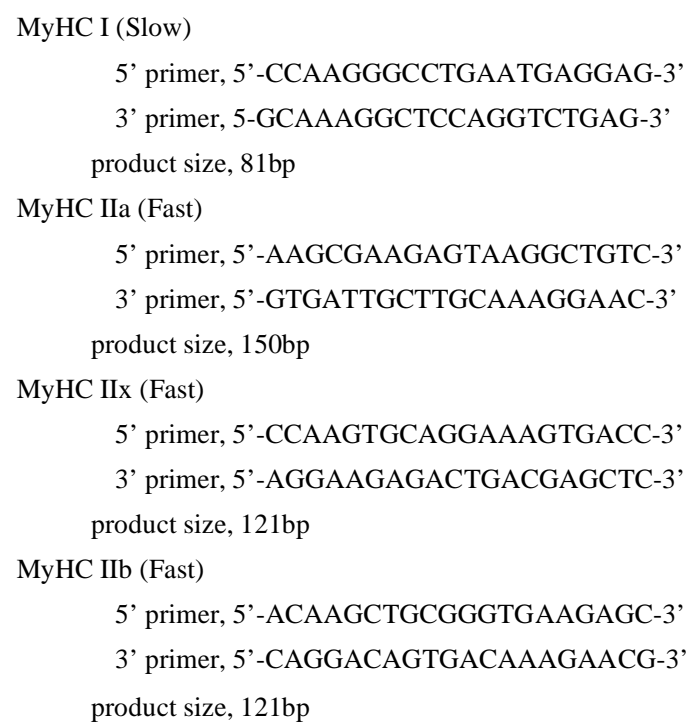

standard curves for all genes studied were more than 0.97 and each dissociation curve contained only a single peak. The quantities of MyHC mRNAs were normalized by the quantity of S16 mRNA. The resulting ratio value was expressed as the percentage relative to the mean value of each target gene of each muscle at 1 week of age set at 100 . The sequences of primers and the sizes of PCR products for MyHC I, IIa, IIx, and IIb were described previously [16] and are shown in Table $\mathbf{1}$.

\section{Statistical Analyses}

A Mann-Whitney $U$ test was used to compare the median values between the $m i / m i$ and $+/+$ mice.

\section{RESULTS}

\section{The Weight of Animals and Muscles}

While the body weights of both the $\mathrm{mi} / \mathrm{mi}$ and $+/+$ mice increased, that of the $+/+$ was $23 \sim 97 \%$ greater ( $\mathrm{p}<0.05 \sim 0.01$ ) than that of the $\mathrm{mi} / \mathrm{mi}$ between 1 and 8 weeks of age (Table 2 ).

The percentage of masseter weight relative to body weight in the $\mathrm{mi} / \mathrm{mi}$ mice increased between 1 and 2 weeks of age, and gradually decreased thereafter, while that of the $+/+$ increased between 1 and 3 weeks of age, and remained stable thereafter (Fig. 3A). The percentage of masseter weight relative to body weight in the $\mathrm{mi} / \mathrm{mi}$ mice was $32 \%$ less than that in the $+/+$ mice at 8 weeks of age $(p<0.05)$. The percentage of gastrocnemius weight relative to body weight showed a similar change, with no significant difference between the $\mathrm{mi} / \mathrm{mi}$ and $+/+$ mice at any time point (Fig. 3B); it increased in the $\mathrm{mi} / \mathrm{mi}$ and $+/+$ mice between 1 and 3 weeks of age, and remained stable until 8 weeks of age.

The Expression of MyHC I mRNA in the Masseter and Gastrocnemius Muscles

Fig. (4) shows the changes in the expression of MyHC I mRNA in the masseter (A) and gastrocnemius (B) muscles between 1 and 8 weeks of age. In the masseter muscle of both the $m i / m i$ and $+/+$, the expression level of MyHC I mRNA was high at 1 week of age and rapidly decreased be-

Table 2. The Weight of Animal

\begin{tabular}{|c|c|c|c|c|c|}
\hline Age (Week) & $\begin{array}{c}+/+ \\
\text { mean } \pm \text { SD }(g)\end{array}$ & $\mathbf{n}$ & $\begin{array}{c}m i / m i \\
\operatorname{mean} \pm \mathrm{SD}(\mathrm{g})\end{array}$ & $\mathbf{n}$ & Significance \\
\hline 1 & $5.30 \pm 0.75$ & 6 & $4.16 \pm 0.63$ & 6 & $\mathrm{p}<0.05$ \\
\hline 2 & $7.52 \pm 0.86$ & 6 & $6.12 \pm 0.84$ & 6 & $\mathrm{p}<0.01$ \\
\hline 3 & $11.2 \pm 1.86$ & 6 & $6.44 \pm 1.28$ & 6 & $\mathrm{p}<0.01$ \\
\hline 8 & $23.9 \pm 3.93$ & 6 & $15.4 \pm 3.20$ & 6 & $\mathrm{p}<0.01$ \\
\hline
\end{tabular}

$\mathrm{n}$ : the number of samples.
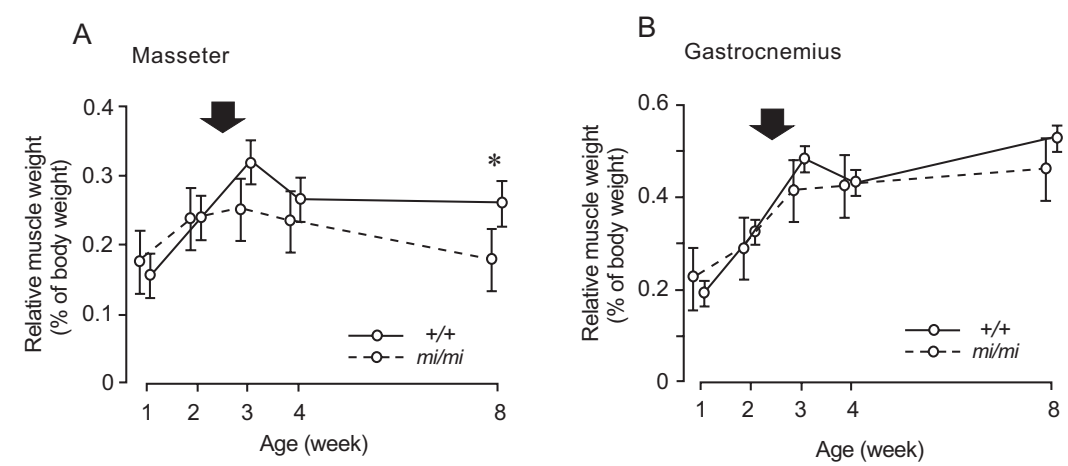

Fig. (3). Changes in the percentage of masseter (A) and gastrocnemius (B) weight relative to body weight at 1, 2, 3, 4, and 8 weeks of age in the $\mathrm{mi} / \mathrm{mi}$ (dotted line) and $+/+$ (solid line) mice. Each point and its vertical bar represent the mean \pm S.D. of six samples. Significant difference between $m i / m i$ and $+/+, * p<0.05$. Arrows indicate the period of weaning. 
A
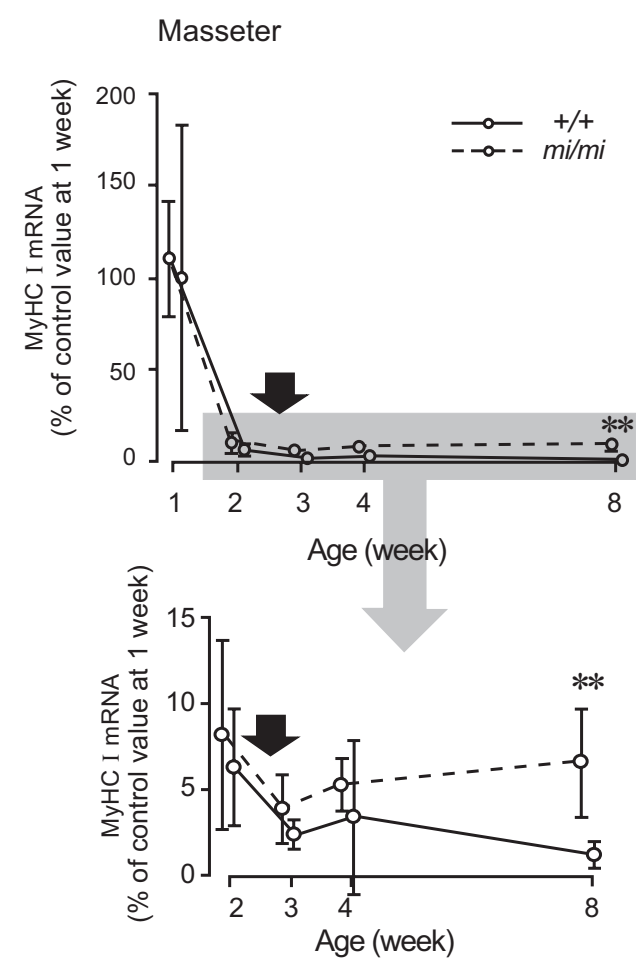

B

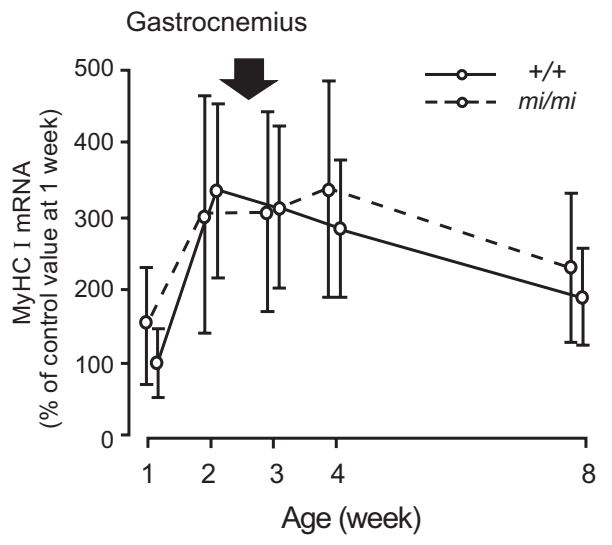

Fig. (4). Relative changes in the expression levels of MyHC I mRNA in the masseter (A) and gastrocnemius (B) muscles at 1, 2, 3, 4, and 8 weeks of age in the $\mathrm{mi} / \mathrm{mi}$ (dotted line) and $+/+$ (solid line) mice. The shadow area of the upper panel in A is enlarged and presented in the lower panel in A. The vertical axis is expressed as a percentage of the mean value of $+/+$ at 1 week of age set at 100 . Each point and its vertical bar represent the mean \pm S.D. of six samples. Significant difference between $m i / m i$ and $+/+{ }^{*} * \mathrm{p}<0.01$. Arrows indicate the period of weaning.

A

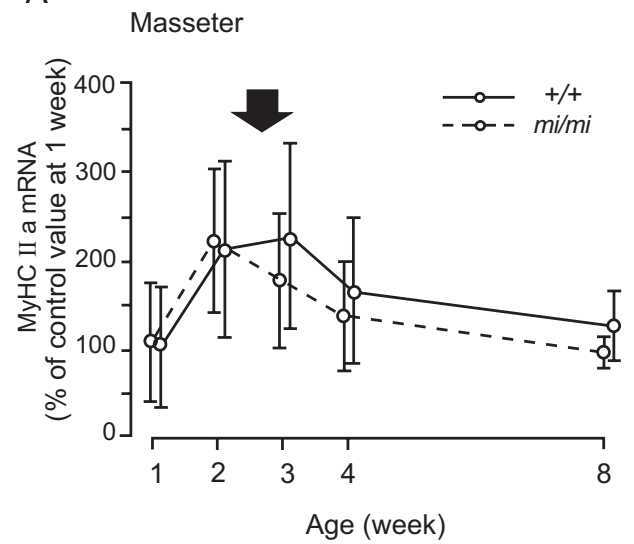

B

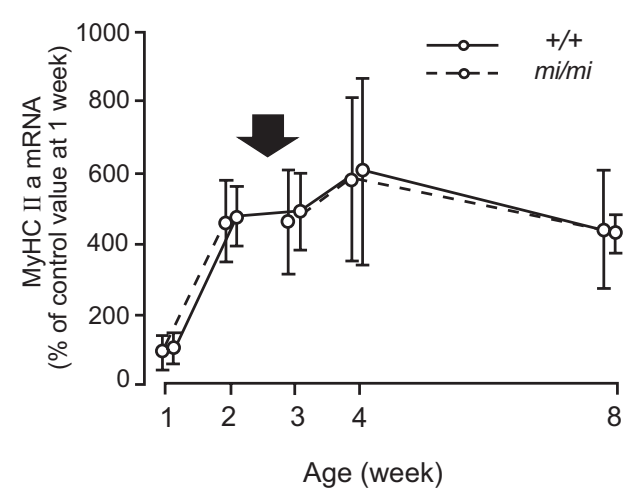

Fig. (5). Relative changes in the expression levels of MyHC IIa mRNA in the masseter (A) and gastrocnemius (B) muscles at 1, 2, 3, 4, and 8 weeks of age in the $\mathrm{mi} / \mathrm{mi}$ (dotted line) and $+/+$ (solid line) mice. Each point and its vertical bar represent the mean \pm S.D. of six samples. Arrows indicate the period of weaning.

tween 1 and 2 weeks. After 2 weeks, the expression level gradually increased in the $\mathrm{mi} / \mathrm{mi}$ mice, whereas it gradually decreased in the $+/+$ mice. At 8 weeks of age, the expression level of MyHC I mRNA in the masseter muscle of the $m i / m i$ mice was 5.1 -fold higher than that in the $+/+$ mice $(\mathrm{p}<0.01)$.

In the gastrocnemius muscle of both the $m i / m i$ and $+/+$, the expression level of MyHC I mRNA increased between 1 and 2 weeks of age, peaked between 2 and 4 weeks, and gradually decreased between 4 and 8 weeks. No significant difference in the expression level of MyHC I mRNA was found between the $m i / m i$ and $+/+$ mice at any time point.

The Expression of MyHC IIa mRNA in the Masseter and Gastrocnemius Muscles

Fig. (5) shows the changes in the expression of MyHC IIa mRNA in the masseter (A) and gastrocnemius (B) mus- 
A

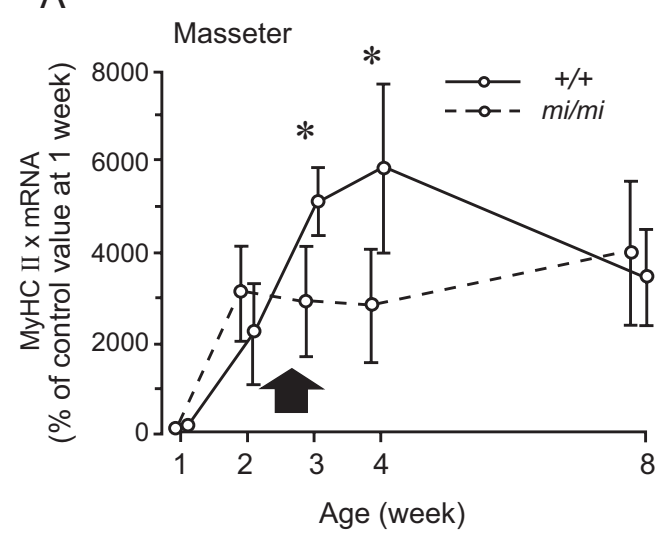

$\mathrm{B}$

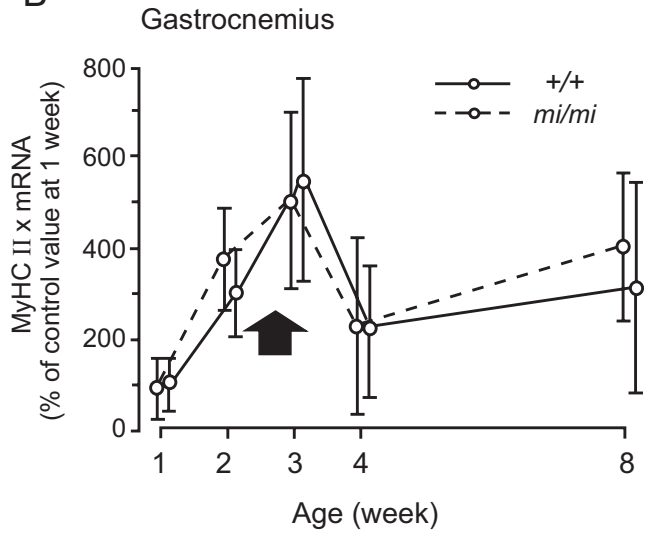

Fig. (6). Relative changes in the expression levels of MyHC IIx mRNA in the masseter (A) and gastrocnemius (B) muscles at 1, 2, 3, 4, and 8 weeks of age in the $m i / m i$ (dotted line) and $+/+$ (solid line) mice. Each point and its vertical bar represent the mean \pm S.D. of six samples. Significant difference between $m i / m i$ and $+/+, * \mathrm{p}<0.05$. Arrows indicate the period of weaning.

A

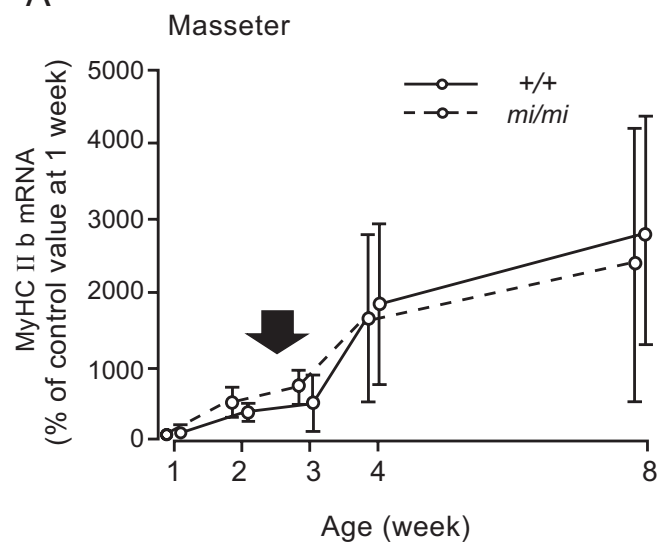

B

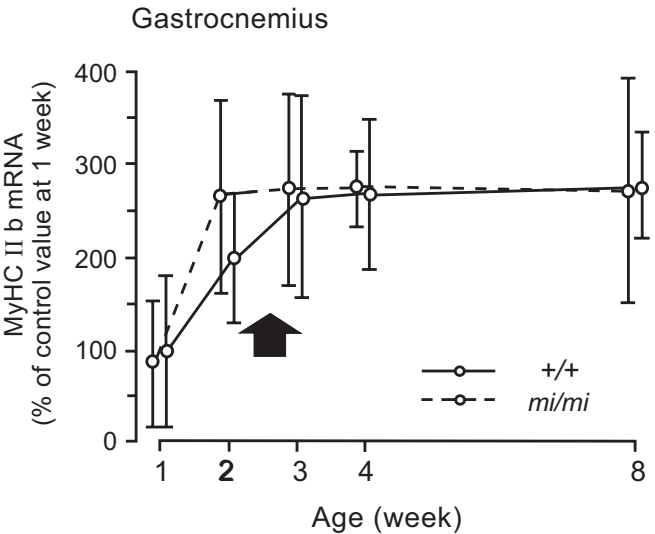

Fig. (7). Relative changes in the expression levels of MyHC IIb mRNA in the masseter (A) and gastrocnemius (B) muscles at 1, 2, 3, 4, and 8 weeks of age in the mi/mi (dotted line) and $+/+$ (solid line) mice. Each point and its vertical bar represent the mean \pm S.D. of six samples. Arrows indicate the period of weaning.

cles between 1 and 8 weeks of age. In the masseter muscle of both the $m i / m i$ and $+/+$, the expression level of MyHC IIa mRNA increased between 1 and 2 weeks of age. After 2 weeks, in the $\mathrm{mi} / \mathrm{mi}$, the expression level gradually decreased whereas, in the $+/+$, it peaked between 2 and 3 weeks, and gradually decreased between 3 and 8 weeks. No significant difference in the expression level of MyHC IIa mRNA was found between the $\mathrm{mi} / \mathrm{mi}$ and $+/+$ mice at any time point.

In the gastrocnemius muscle, changes in the expression level of MyHC IIa were mostly consistent between the $m i / m i$ and $+/+$. The expression level of MyHC IIa mRNA increased between 1 and 4 weeks of age, and then gradually decreased until 8 weeks of age. No significant difference in the expression level of MyHC IIa mRNA was found between the $m i / m i$ and $+/+$ mice at any time point.

\section{The Expression of MyHC IIx mRNA in the Masseter and Gastrocnemius Muscles}

Fig. (6) shows the changes in the expression of MyHC IIx mRNA in the masseter (A) and gastrocnemius (B) muscles between 1 and 8 weeks of age. In the masseter muscle of the $\mathrm{mi} / \mathrm{mi}$, the expression level of MyHC IIx mRNA increased between 1 and 2 weeks, and remained relatively stable thereafter. In the masseter muscle of the $+/+$, the expres- sion level of MyHC IIx mRNA continued to increase between 1 and 4 weeks of age, and decreased thereafter, until 8 weeks of age. The expression levels of MyHC IIx mRNA in the $\mathrm{mi} / \mathrm{mi}$ mice were $41 \%$ and $55 \%$ less than those in the $+/+$ mice at 3 weeks and 4 weeks of age, respectively $(\mathrm{p}<0.05)$.

The gastrocnemius muscle of both the $m i / m i$ and $+/+$ mice exhibited a very similar pattern of MyHC IIx during postnatal development. The expression levels of MyHC IIx mRNA in both the $\mathrm{mi} / \mathrm{mi}$ and $+/+$ mice increased between 1 and 3 weeks of age, decreased between 3 and 4 weeks of age, then slightly increased until 8 weeks of age. No significant difference in the expression levels of MyHC IIx mRNA was found between the $m i / m i$ and $+/+$ mice at any time point.

\section{The Expression of MyHC IIb mRNA in the Masseter and Gastrocnemius Muscles}

Fig. (7) shows the changes in the expression of MyHC IIb mRNA in the masseter (A) and gastrocnemius (B) muscles between 1 and 8 weeks of age. The masseter muscle of both the $\mathrm{mi} / \mathrm{mi}$ and $+/+$ showed a very similar pattern of MyHC IIb during the postnatal development. The expression level of MyHC IIb mRNA gradually increased between 1 and 8 weeks of age. No significant difference in the expres- 
sion levels of MyHC IIb mRNA was found between the $\mathrm{mi} / \mathrm{mi}$ and $+/+$ mice at any time point.

In the gastrocnemius muscle, the expression levels of MyHC IIb mRNA increased between 1 and 3 weeks of age in the $+/+$ mice, and between 1 and 2 weeks of age in the $\mathrm{mi} / \mathrm{mi}$ mice; it remained stable thereafter in both strains. No significant difference in the expression levels of MyHC IIb mRNA was found between the $m i / m i$ and $+/+$ mice at any time point.

\section{DISCUSSION}

MyHC I is reported to disappear during the postnatal development of masseter muscle in the wild-type mouse and is not detectable in the adult masseter muscle $[16,17]$. In the present study, in the masseter muscle of $+/+$ mice, MyHC I nearly disappeared at 8 weeks of age, whereas, in the $\mathrm{mi} / \mathrm{mi}$ mice, it was still detected at 8 weeks of age. We previously reported that the embryonic type of the nicotinic acetylcholine receptor subunit is still expressed in the masseter muscle of $\mathrm{mi} / \mathrm{mi}$ mice at 8 weeks of age, although it was not detected in the $+/+$ mice [14]. These results suggest that the development of the masseter muscle is slower in $\mathrm{mi} / \mathrm{mi}$ mice compared with $+/+$ mice.

In the present study, we observed a marked difference in the expression of MyHC IIx at 3 and 4 weeks of age between the $m i / m i$ and $+/+$ mice. This is the same period during which the feeding behavior of the $+/+$ mice changes from suckling to chewing [3]. Thus, the observed differences may be attributable to the deficiency of teeth in the $\mathrm{mi} / \mathrm{mi}$ mice. Since MyHC IIx is reported to be the predominant isoform $[16,17]$, the deficiency of teeth in the $\mathrm{mi} / \mathrm{mi}$ mice may transiently affect these properties of the masseter muscle during postnatal development.

It is said that there has recently been concern that children no longer need to chew their food extensively due to the popularization of softer so-called 'fast foods'. In the present study, the percentage of masseter weight relative to body weight in the $\mathrm{mi} / \mathrm{mi}$ mice was significantly less than that in the $+/+$ mice at 8 weeks of age. Together with the findings regarding MyHC I and IIx expression, the present findings suggests that proper chewing is essential for the normal growth of the masseter muscle, and that it is essential to provide a diet that induces proper occlusal activity for the normal growth of the mouse masseter muscle. The present findings also seem to be useful and interesting basic information for orthodontic science, the goal of which is to improve the occlusal function. Further studies using human seem necessary to directly associate our present results with possible influences in human.

The mitf gene is reported to be expressed in various tissues containing skeletal muscle, heart muscle, and mast cells [18], but no marked defects have been observed in the skeletal muscles of $\mathrm{mi} / \mathrm{mi}$ and mitf null mice [13]. In the present control conditions using the gastrocnemius muscles of $\mathrm{mi} / \mathrm{mi}$ mice, there was no significant difference in the expression levels of MyHC isoform mRNAs between the $\mathrm{mi} / \mathrm{mi}$ and $+/+$ mice. This seems to exclude the possibility that the mutation of mitf itself affects the expressions of MyHC isoform mRNAs.
In the present study, there was no significant difference in the expression levels of MyHC IIa and IIb mRNAs between the $\mathrm{mi} / \mathrm{mi}$ and $+/+$ mice. It was previously reported that the ratio of MyHC IIb-positive fibers to the total number of fibers in the masseter muscle of $\mathrm{mi} / \mathrm{mi}$ mice at 4 and 9 weeks of age is lower than that in $+/+$ mice, whereas that of MyHC IIa in $m i / m i$ is higher than that in $+/+$ mice [19]. This inconsistency is probably due to differences in methodology: in the present study, the level of MyHC mRNA in the whole masseter muscle was determined using real-time PCR whereas, in the previous study, limited areas of the masseter were analyzed using an immunohistochemical method [19], even though regional differences in the distribution of MyHC isoforms had been previously reported [20].

We previously reported differences in the expressions of MyHC isoform mRNA of masseter muscle between rats fed a pellet diet and those on a liquid diet $[21,22]$. Since, in the present study, the $\mathrm{mi} / \mathrm{mi}$ and $+/+$ were fed a powder and pellet diet, respectively, the observed difference between these two strains may have reflected the influence of diet. To exclude this possibility, the levels of MyHC isoform mRNAs were analyzed in the masseter muscle of $+/+$ mice at 8 weeks of age which were fed a powder or pellet diet after weaning (around 3 weeks of age) (Supplemental material). The two different diets produced no significant differences in the expressions of MyHC isoform mRNAs in the masseter muscle. This result appears to be inconsistent with our previous results $[21,22]$, but probably due to the difference between liquid and powder diets, and between rats and mice. Thus, in the present study, the observed differences between the $\mathrm{mi} / \mathrm{mi}$ and $+/++$ mice appear to be related to the deficiency of teeth.

\section{CONCLUSIONS}

In conclusion, from these results, we speculate that the deficiency of teeth affects the masseter muscles during the postnatal development, proper chewing is essential for the normal growth of the masseter muscle, and it is essential to provide a diet that induces proper occlusal activity for the normal growth of the mouse masseter muscle.

\section{ACKNOWLEDGEMENTS}

We gratefully acknowledge Professor Emeritus Kunimichi Soma, Dr. Yoshiro Matsumoto and Dr. Jun Hosomichi of Orthodontic Science, Graduate School of Tokyo Medical and Dental University for their support and encouragement throughout the study. In addition, we would like to thank all members of Orthodontic Science, Graduate School of Tokyo Medical and Dental University for their encouragement throughout the study. This study was supported in part by grant-in-aid for funding scientific research (No. 20592190 to A.Y.).

\begin{tabular}{|c|c|c|c|}
\hline \multicolumn{4}{|c|}{ ABBREVIATIONS } \\
\hline mitf & $=$ & $\begin{array}{l}\text { microphthalmia-associated } \\
\text { tion factor gene }\end{array}$ & transcrip- \\
\hline МyHC & $=$ & Myosin heavy chain & \\
\hline PCR & $=$ & Polymerase chain reaction & \\
\hline RT & $=$ & Reverse transcription & \\
\hline
\end{tabular}




\section{SUPPLEMENTARY MATERIAL}

Supplementary material is available on the publishers Web site along with the published article.

\section{REFERENCES}

[1] Yamane A, Fukui T. Characteristics of masticatory and tongue muscles. J Oral Biosci 2007; 49: 206-10.

[2] Yamane A. Embryonic and postnatal development of masticatory and tongue muscles. Cell Tissue Res 2005; 322: 183-9.

[3] Maeda N, Hanai H, Kumegawa M. Postnatal development of masticatory organs in rats. III. Effect of mastication on the postnatal development of the M. masseter superficialis. Anat Anz 1981; 150: 424-7.

[4] Maeda N, Hanai H, Kumegawa M. Postnatal development of masticatory organs in rats. I. Consecutive changes in histochemical properties and diameter of muscle fibers of the M. masseter superficialis. Anat Anz 1981; 149: 319-28.

[5] Miyata H, Sugiura T, Wada N, Kawai Y, Shigenaga Y. Morphological changes in the masseter muscle and its motoneurons during postnatal development. Anat Rec 1996; 244: 520-8.

[6] Kubota K, Narita N, Ohkubo K, et al. Morphological studies of the neuromuscular mechanism shifting from sucking to biting of mice. Acta Anat 1988; 133: 200-8.

[7] Saito T, Ohnuki Y, Saeki Y, et al. Postnatal changes in the nicotinic acetylcholine receptor subunits in rat masseter muscle. Archs Oral Biol 2002; 47: 417-21.

[8] Schiaffino S, Reggiani C. Molecular diversity of myofibrillar proteins: Gene regulation and functional significance. Physiol Rev 1996; 76: 371-423.

[9] Pette D, Staron RS. Mammalian skeletal muscle fiber type transitions. Int Rev Cytol 1997; 170: 143-223.

[10] Hallsson JH, Favor J, Hodgkinson C, et al. Genomic, transcriptional and mutational analysis of the mouse microphthalmia locus. Genetics 2000; 155: 291-300.

[11] Steingrimsson E, Moore KJ, Lamoreux ML, et al. Molecular basis of mouse microphthalmia (mi) mutations helps explain their devel- opmental and phenotypic consequences. Nat Genet 1994; 8: 25663.

[12] Symons AL, Powell RN, Seymour GJ, Harbrow DJ. Disturbances of tooth form and eruption in the microphthalmic (mi) mouse: a light and electron microscopic study. Archs Oral Biol 1989; 34: 716.

[13] Steingrimsson E, Tessarollo L, Pathak B, et al. Mitf and Tfe3, two members of the Mitf-Tfe family of bHLH-Zip transcription factors, have important but functionally redundant roles in osteoclast development. Proc Natl Acad Sci USA 2002; 99: 4477-82.

[14] Kota Y, Yamane A, Tomohiro T, Asada Y. Contribution of Occlusal Activity to Synaptogenesis in Masticatory Muscles. J Dent Res 2009; 88: 768-72.

[15] Yamane A, Mayo M, Shuler C, et al. Expression of myogenic regulatory factors during the development of mouse tongue striated muscle. Archs Oral Biol 2000; 45: 71-8.

[16] Sartorius CA, Lu BD, Acakpo-Satchivi L, Jacobsen RP, Byrnes WC, Leinwand LA. Myosin heavy chains IIa and IId are functionally distinct in the mouse. J Cell Biol 1998; 141: 943-53.

[17] Lu BD, Allen DL, Leinwand LA, Lyons GE. Spatial and temporal changes in myosin heavy chain gene expression in skeletal muscle development. Dev Biol 1999; 216: 312-26.

[18] Hodgkinson CA, Moore KJ, Nakayama A, et al. Mutations at the mouse microphthalmia locus are associated with defects in a gene encoding a novel basic-helix-loop-helix-zipper protein. Cell 1993; 74: 395-404.

[19] Doi T, Abe S, Ide Y. Masticatory function and properties of masseter muscle fibers in microphthalmic $(\mathrm{mi} / \mathrm{mi})$ mice during postnatal development. Ann Anat 2003; 185: 435-40.

[20] Widmer CG, Morris-Wiman JA, Nekula C. Spatial distribution of myosin heavy-chain isoforms in mouse masseter. J Dent Res 2002; 81: 33-8.

[21] Saito T, Fukui K, Akutsu S, et al. Effects of diet consistency on the expression of insulin-like growth factors (IGFs), IGF receptors and IGF binding proteins during the development of rat masseter muscle soon after weaning. Archs Oral Biol 2004; 49: 777-82.

[22] Saito T, Ohnuki Y, Yamane A, Saeki Y. Effects of diet consistency on the myosin heavy chain mRNAs of rat masseter muscle during postnatal development. Archs Oral Biol 2002; 47: 109-15.

(C) Katayama et al.; Licensee Bentham Open.

This is an open access article licensed under the terms of the Creative Commons Attribution Non-Commercial License (http://creativecommons.org/licenses/by-nc/3.0/) which permits unrestricted, non-commercial use, distribution and reproduction in any medium, provided the work is properly cited. 